\title{
Cultivating on Intercultural Communicative Competence for Overseas Students in China
}

\author{
Hui Li \\ Teaching and Research Institute of Foreign Languages, Bohai University, Jinzhou, 121013, China \\ nancylh@126.com
}

Keywords: overseas student; intercultural communicative competence; competence composition; cultivating ways

\begin{abstract}
This paper takes the basic theory as a guide, first of all, the study of the construction of intercultural communication competence, including knowledge, emotional factors, situational characteristics and mental activity characteristics; Then, it studies the target structure of intercultural communication, including language skills, language knowledge, learning strategies, emotional attitude and cultural knowledge; At last, this article puts forward the ways to cultivate intercultural communicative competence, including the strengthening of communication with overseas students, the management of the convergence of overseas students, and the strengthening of the cross-cultural training and the construction of the social support system. The research results of this paper can help the students to face the difficulties in cross-cultural adaptation and better integrate into Chinese culture and life, improve the education level of overseas students in china.
\end{abstract}

\section{Introduction}

Intercultural communication is the communication between people with different cultural backgrounds. Cultural differences will have an impact on cross-cultural communication. Cultural differences are reflected in all aspects of culture, such as religious beliefs, values, ways of thinking, life style, interpersonal relations and so on. The greater the cultural differences, the more likely it is to cross cultural communication. With the social development and economic globalization, people are increasingly exposed to different cultural backgrounds and different countries [1].With the development of science and technology, the distance between people is getting shorter and the communication and integration between different cultures has become an important feature of this era. In recent years, China's overseas students education is booming, Chinese overseas students education began to integrate into the global education market, in the WTO framework, and the national university competition, to compete and occupy the world's largest market share, there will be more and more students in China study and life. Chinese academic circles for the study of overseas students to adapt to the problem of Chinese students learning and further education in the developed countries as the research object, while the domestic study of overseas students in China is very little. The daily life experience of Chinese students in the study is a breakthrough point, and it is based on a large number of first-hand information on the life, learning, and communication with the Chinese people. Through the theoretical analysis of the system, to solve the problem of intercultural communicative competence of overseas students in china.

\section{Composition on Intercultural Communicative Competence}

Cross cultural communication is a process of communication between the two parties, both verbal and nonverbal, the successful communication between the two sides to achieve the success of the communication and the main factors of knowledge, emotional factors, situational characteristics and mental activity characteristics, the structure of the model is shown in Fig. 1 [2,3].

(1) Knowledge factors. Knowledge factor refers to the degree that the communication object is located in the culture, and the more the other culture, the stronger the cross culture ability. Communicators should understand the values and beliefs of the target culture, to understand the 
cultural patterns of the communication object, and also to master the language of the target language and the non verbal communication script.

(2) Emotional factors. Emotional factors refer to the attitude of the communicators to the communicative objects and intercultural communication. The important feature is the anxiety of the cross culture communication, which is the feeling of fear and anxiety in the cross culture communication.

(3) Mental activity characteristics. Mental activity factor is the embodiment of knowledge and emotional factors, including verbal and non-verbal expression and role play. Speech expression refers to how the individual uses language. Communicators may know a lot of language knowledge, but the pragmatic ability is very poor, can not be used in the actual dialogue to express the target language.

(4) Situational characteristics. Individuals may have a strong communication ability in a certain context, but in other contexts, it is not easy to deal with. Therefore, the quality of the communicative competence is influenced by the context, which influences the ability of intercultural communication, including the environmental context, the pre contact, the status difference and the interference of the third parties, etc..

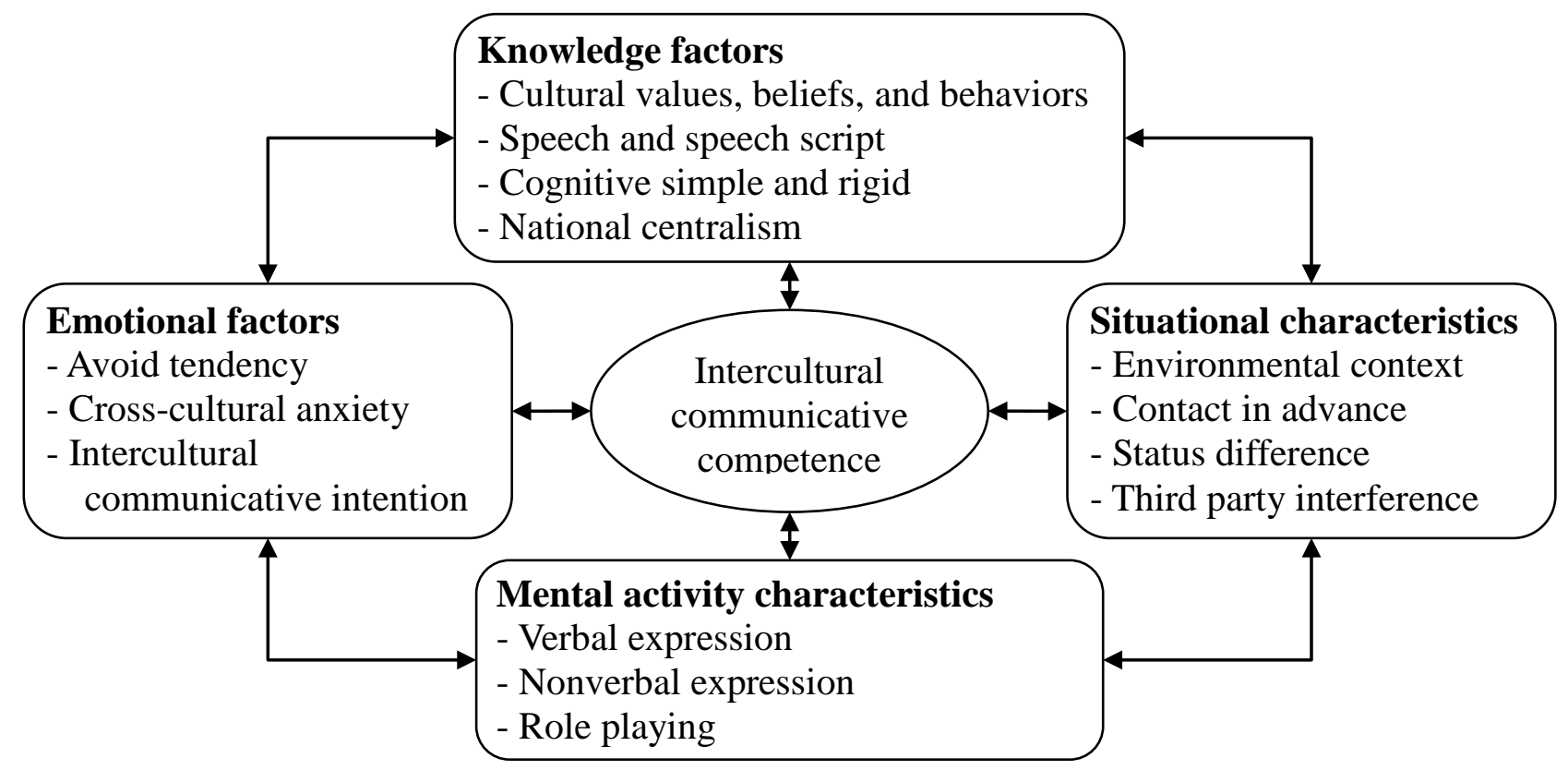

Fig. 1. Structure model on intercultural communicative competence

\section{Target Structure on Intercultural Communicative Courses}

Cross cultural communication is a compulsory course for overseas students in China, which aims to improve the intercultural communication competence of overseas students, broaden their international perspective, and help students to solve the problems caused by cultural differences in intercultural communication. Through the course of study, students can understand the relationship between language, culture and communication of the three, to adapt to various forms of communication; To have a better understanding of Chinese culture, and to communicate effectively, and to avoid misunderstanding due to different cultural expectations; Interpretation of gestures and other forms of body language; the discussion of the cultural adaptation and the compatibility of the problem, and ultimately to cultivate and improve the students' intercultural communication ability. Course target structure is shown in Fig. 2.

As can be seen from Fig. 2, the course objectives mainly include 5 aspects:

(1) Language skills. Language specifically refers to the exact words, understand the meaning, structure correct labeling, concise statement, smooth knowledge of Arts and science, plain language, conform to the standard, the concept of objective expression clear, accurate, consistent, decent, no wording. Including listening, speaking, reading and writing four aspects. Research and practice 
shows that people's language ability is based on the physical quality of the language, through the communication with adults or the system of education and gradually developed.

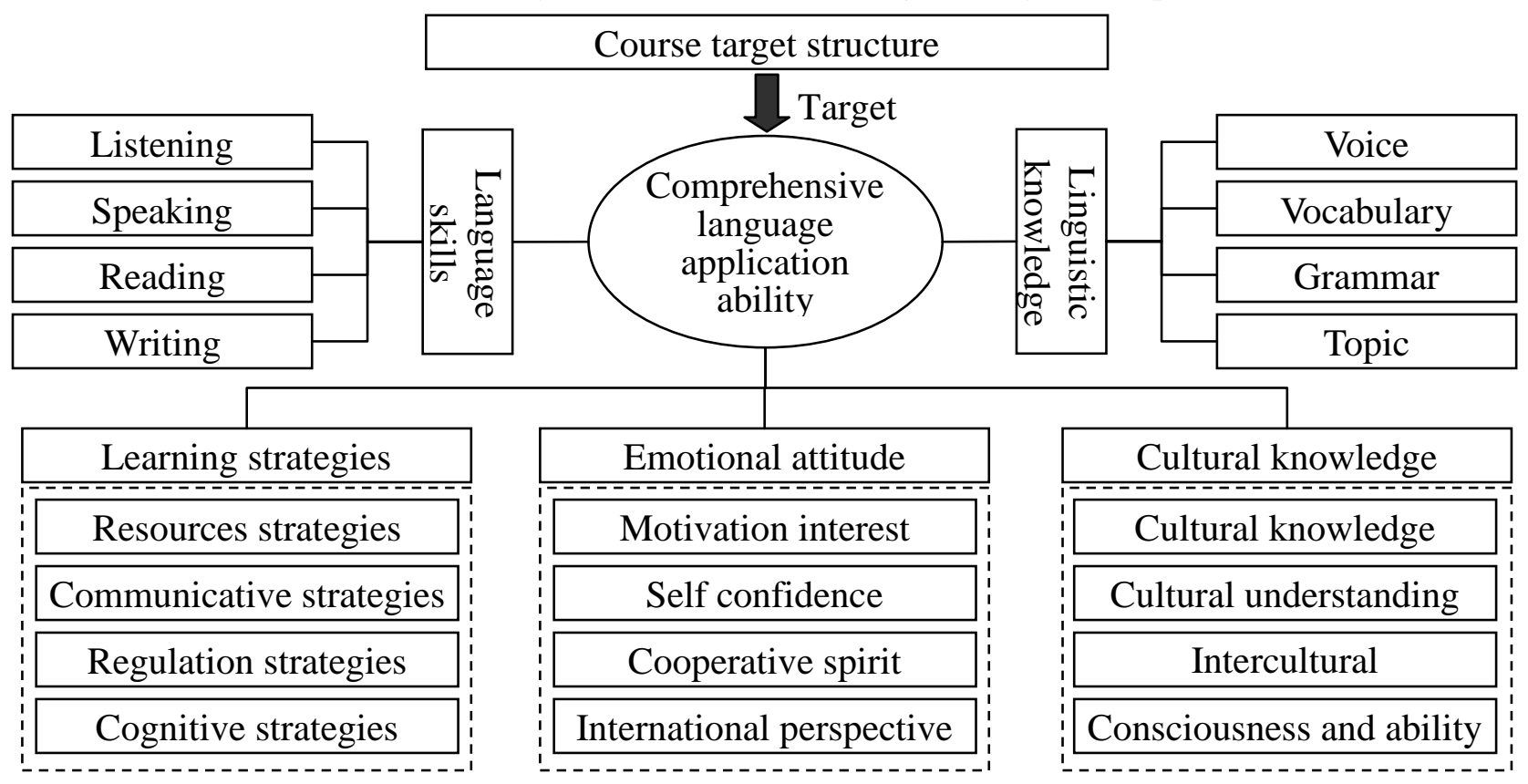

Fig. 2. Course target structure

(2) Language knowledge. Language knowledge is the component of language ability, which is an important basis for developing language skills. Foreign language teaching theory thinks that language knowledge and language skills are simultaneously developed. Learning from the first word, the first sentence to start, you begin to learn language knowledge, develop language skills.

(3) Learning strategies. Learning strategy is a kind of psychological activity, which is accompanied by the learning process of the learners. It is a kind of arrangement of the learning process. According to the role of learning strategies, divided into two types of basic strategies and support strategies. The basic strategy is to refer to a variety of learning strategies, mainly including information access, storage, information retrieval and application strategy.

(4) Emotional attitude. In language teaching, emotion is the personality factor of interest, attitude, motivation, confidence, autonomy and will affect the learning process and effect. Emotional attitude is all manner of experience, the core meaning is as a kind of psychological process, reflecting the relationship between objective things and people's needs.

(5) Cultural knowledge. The use of cross cultural communication and related knowledge of the cultural impact of the reasons, to overcome cultural barriers, improve the ability to adapt to foreign cultures and cross cultural cooperation. Master the characteristics and types of different cultures, and analyze the reasons of cultural conflicts. Improve students' communicative competence and cultural appreciation.

\section{Cultivating Ways on Intercultural Communicative Competence}

Through careful research and analysis and combined with the results of previous studies, this paper puts forward the way to cultivate intercultural communicative competence of overseas students in China is as follows [4-6]:

(1) Strengthen communication and exchanges with overseas students in china. Cross cultural communication refers to the process that people with different cultural backgrounds exchange their own unique culture to each other, and more to express the cultural exchange, which includes the comparison between different cultures, and the core is the existence of different cultures. Cross cultural communication to transfer information between people of different cultural background, influences each other in different cultural background there are differences in the understanding of information, communication between there is no difference in cultural status, the core is under the 
premise of seeking similarities. No information and communication, no doubt in the free outside the local community, it is easy to produce the feeling of isolation. Therefore, the establishment of an effective communication mechanism, so that they have a deeper understanding of Chinese society and culture. Mutual understanding, eliminate misunderstanding, transfer information, enhance friendship, timely discovery of the problem, the ability to promote cross-cultural communication has a role in promoting. One is that the information flow in time, to provide students with adequate sources of information, so that they integrate into the local community, the management of local events in a timely manner to inform them, so that they have a sense of belonging; Two is to encourage foreign students to participate in the social and cultural life of China, and to put forward an honest opinion of the Chinese education system and management; The three is to provide a variety of ways of communication, not only to maintain the work level, but also to maintain the personal level and the usual informal level, so that they get from other channels can not get the information; Four is the establishment of smooth, effective communication mechanism within the school, the relevant departments to blame the division of clear division of labor.

(2) On the implementation of the convergence of the overseas students in china. As a way of managing foreign students in the world, it can provide the students with equal opportunities for learning and evaluation from different cultural backgrounds. First, the convergence of management for students' cultural diversity, and therefore the face of the diversity of culture; second, the convergence of management is not equal to the assimilation management, not simply requires other cultures to adapt to a culture, but the mutual influence between different cultures; Again, in the convergence management system, students' cultural background is recognized and respected, students have the opportunity to know and learn from their own different cultures, so that they are in a multicultural learning environment; finally, in the convergence management environment, students not only have equal opportunities to learn, but also have an equal opportunity to be evaluated. The two aspects of teaching management and life management. The convergence of teaching management is an effective measure to improve the quality of education. The education and professional education should be in the direction of convergence, such as online courses, automatic query results, teaching practice and other management methods which should be extended to students, as far as possible the students into the teaching management system of Chinese students. In the life management of overseas students in China, regardless of nationality and background of foreign students, the first should be treated as a student, the second is considered to be foreigners. On the one hand, according to the strict management of the students' requirements, on the other hand, according to the different cultural background of the implementation of human management.

(3) Enhancing cross culture training for overseas students in china. The purpose of intercultural communicative competence training is to enhance cross-cultural awareness and intercultural communicative competence, to develop understanding and respect for cultural differences, and to eliminate cultural differences in understanding and communication, so that two kinds of culture set in one. Cultivating way is an important way to form the cultural adaptation of foreign students, but also an important means to enhance the cultural empathy. Cultural empathy is a kind of psychological experience, the emotional displacement, cognitive transformation, that is, consciously or unconsciously, beyond the cultural stereotype of the national language, and the psychological tendency of the station in a different culture mode. Which can ensure the smooth communication between different cultures. Cultural empathy ability is the gradual accumulation of the formation through the practice of cross culture communication. First, it is to cultivate the cultural sensitivity of the communicators, to effectively shorten the subject and object of the same information generated by different cognitive distance, we should strengthen the cultural sensitivity training, to improve the response and adaptation of different cultures, and promote the communication and understanding between people of different cultures; Secondly, it is the cultivation of the ability to adapt to the culture, so that the students will adapt to the Chinese culture as soon as possible.

(4) Construction of social support system for international students' intercultural communication. The society provides the support for the students to study, life, emotion, communication and 
cognition, and improve the application ability of foreign language as the communicative language, alleviate the pressure of the cultural adaptation, and reduce the uncertainty and anxiety in the heterogeneous culture, and quickly integrate into the new learning and living environment. Including macro and micro two aspects. On the macro, improve the social support network, the main strategy of overseas students in china: First, to realize the transformation from the political affairs to the foreign affairs of education, improve the practical education policies and regulations of China's higher education, and expand the channels of foreign students' education and create a good international reputation; Second, schools based on the students enrollment and management departments, the establishment of cross cultural psychological counseling and language support system, in order to teach college students, scientific research institutes to establish academic support system, strengthen the management of students in Colleges and universities in china; Third, through the construction of inclusive, diverse forms of multicultural student organizations established with fellow directors, the alumni association is relying on China's students autonomous organizations. At the micro level, it is not only a need for school management, but also the concern and attention of the relevant departments, organizations and even their own citizens.

\section{Conclusion}

The increasing number of overseas students in China, the study of intercultural communication competence is the need to strengthen the effective management of foreign students, improve the training level and improve the competitiveness of our country in the international market. Intercultural communication brings about not only the novelty and the mystery, the more pressure, it is a full of dreams and challenges. The differences between language and culture further aggravate the communication difficulties of overseas students. The failure of intercultural communication leads to the failure of overseas students, leading to the completion of their studies, and some even lead to serious mental illness or tragedy. The research content of this paper is to solve some problems in intercultural communication, improve the service and management system, improve the understanding of Chinese and foreign students, and promote the adaptability of students in China, too help international students in the face of the difficulties in cross-cultural adaptation, so as to improve their learning level as soon as possible, to better integrate into Chinese culture and life, to improve the level of education in our country.

\section{References}

[1] Levent Uzun, "Utilising Technology for Intercultural Communication in Virtual Environments and the Role of English," Procedia - Social and Behavioral Sciences, vol. 116, no. 21, pp. 2407-2411, 2014.

[2] L. Gao, F. Wang, "A tentative approach to intercultural communicative competence," Journal of Northwest University, vol. 37, no. 3, pp. 116-119, 2007.

[3] Baidu library, "Intercultural communicative competence," http://wenku.baidu.com/link?url=pr-uORfEpQMV8IXfk5OjvMHNZBLPFOJ9xpNGW8SL231 P3xXVtwOsyd1Rxmz29N6wICHxxW69Mj5VB1s11kUF00FLOs-5eE9RxLBosy, 2015-8-21.

[4] Reynaldo Anderson, "MolefI Kete Asante: The Afrocentric Idea and the cultural turn in intercultural communication studies," International Journal of Intercultural Relations, vol. 36, no. 6, pp. 760-769, 2012.

[5] X. Y. Wang, "Cross cultural communication and training of College Students' intercultural communicative competence," Journal of Hehai University(Philosophy and Social Sciences), vol. 13, no. 1, pp. 85-88, 2011.

[6] Bilgehan Gültekin, "Dialog and Mediation Education in Intercultural Communication," Procedia - Social and Behavioral Sciences, vol. 55, no. 5, pp. 1124-1133, 2012. 